\begin{tabular}{lc}
\hline CURRENT & ISSN: 0973-4929, Vol. 13, №. (2) 2018, Pg. 251-258 \\
WORLD & Current World Environment
\end{tabular}

ENVIRONMENT

Journal Website: www.cwejournal.org

\title{
Ergonomics Hazards and Musculoskeletal Disorders Among Workers of health Care Facilities
}

\author{
ALMAS HAMID*, ALIZAE SALAAM AHMAD, SARAH DAR, \\ SANA SOHAIL, FAIZA AKRAM and MARIYA IRFAN QURESHI
}

Department of Environmental Sciences, Kinnaird College for Women, Lahore, Pakistan.

\begin{abstract}
The present study was conducted to determine occupational health and safety hazards with special focus on ergonomic hazards among healthcare facility (HCF) workers. A structured questionnaire survey was conducted among 200 workers in five HCFs of Lahore, Pakistan. Among the reported ergonomic hazards, muscle aches/ sprains (76.5\%), elbow/ wrist/ neck pain (56.0\%), body posture issues (56.0\%), excessive stretching of muscles $(67.5 \%)$ and bending/ twisting at work (55.5\%) were commonly encountered. Biological hazards included incidences of cuts/wounds/ lacerations (69.0\%), contact with specimens (56.0\%), exposure to airborne diseases (64.0\%) and other infections $(72.0 \%)$ inspite of the fact that majority $(90.0 \%)$ were aware of procedures where needle stick injuries are most likely to occur and knowledgeable on occupational infections. Physical hazards included slips/trips/falls (65.0\%), high noise levels $(64.0 \%)$ and chemical spills $(54.0 \%)$. A significant percentage of workers experienced psychosocial hazards including work related stress $(77.0 \%)$ and some form of psychosocial or physical abuse (68.5\%). Despite workers awareness about occupational health hazards and implementation of control measures by HCF to mitigate hazards (especially biological) prevalence of hazards was reported. Hence, there is a need to improve working standards and conditions to reduce the occurrence of ergonomic and psychosocial hazards.
\end{abstract}

\section{Introduction}

Healthcare is, directly or indirectly, associated with the provision of health facilities to individuals. The healthcare facilities (HCF) involve a broad range of workforce such as physicians, nurses, experts, clinical research/ laboratory personnel, social and administrative workers ${ }^{1}$. Health care services around the world employ over 59 million personnel who are daily exposed to a variety of health and safety hazards. Healthcare, an important sector of the U.S. economy provides employment to over 8 million U.S. healthcare workers (HCW), including pharmacy and nursing workers, physicians, operative room staffs, environmental facilities employees, personnel in

CONTACT Almas Hamid almas209@yahoo.com

\section{Article History}

Received: 13 February 2018

Accepted:11 April 2018

\section{Keywords}

Healthcare workers, Healthcare facilities, Musculoskeletal disorders,

Ergonomics.

Lahore, Pakistan.

(c) 2018 The Author(s). Published by Enviro Research Publishers.

This is an 6 Open Access article licensed under a Creative Commons license: Attribution 4.0 International (CC-BY).

Doi: http://dx.doi.org/10.12944/CWE.13.2.10 
examination laboratories, veterinary care staffs and those involved in shipping and receiving patients, who are potentially exposed to dangerous drugs as well as diverse hazards ${ }^{2}$.

Common hazards experienced by HCW include biological, ergonomics, physical and psychosocial hazards. Biological hazards comprise needle stick injuries, exposure and susceptibility to infections such as tuberculosis, hepatitis and HIV/ AIDS occurring through direct and indirect body contact. Physical hazards include slips trips and falls, exposure to noise and chemicals such as glutaraldehyde, ethylene oxide and drugs. While violence, stress and anxiety due to work constitute psychosocial hazards ${ }^{3}$.

Work related musculoskeletal disorders (WMSDs) are most often experienced by medical professionals with surgeons being the most susceptible, followed by nurses and physiotherapists ${ }^{4}$. Ergonomic hazards including problems related to backbone, neckline, shoulder and knees are common complaints among medical, dental and nursing professionals ${ }^{5}$.

The HCW face high ergonomic risks and therefore have greater potential for musculoskeletal issues along with other work associated injuries. According to an estimate, more than 5000 injuries among HCW have been reported annually. These are mainly attributed to manual handling of patients and excessive workloads. Moreover, awkward or static postures during treatment of patients result in stresses and strains which is another cause of such problems ${ }^{6}$. According to an estimate, one third of all cases of sick leave among health care employees are due to musculoskeletal disorders (MSDs). Even in developed countries, MSDs among $\mathrm{HCW}$ are generally under reported ${ }^{4}$. The MSDs affect body movements, cause wounds or dys functions of nerves, tendons, muscles, cartilagebone, spinal discs and joints. These disorders comprise soreness, connective tissue damage, pain in back, hernia, problems of shoulder and knee tears ${ }^{7}$. According to National Institute for Occupational Safety and Health (NIOSH), numerous studies indicated direct relationship between physical work and occupational related MSDs. Several aspects that are related with MSD include constant body posture, persistent sitting positions, continuous movement, unnecessary use of force and prolonged standing ${ }^{8}$.
Many programs on psychosocial nature of humans, physical work and medical facilities related to the prevention and effective management of MSDs have been conducted by NIOSH and OSHA .

Keeping in view the significance of $\mathrm{OH} \& \mathrm{~S}$, the current study aimed to determine various occupational hazards, especially ergonomic hazards, faced by different types of HCW, assess the level of awareness among workers regarding occupational hazards and to identify control measures provided by the employers as well as those adopted by the workers to mitigate and minimize the prevalent occupational hazards.

\section{Materials and Methods}

A descriptive cross-sectional study was conducted among 200 health care workers employed at five government and private HCFs in Lahore, Pakistan. The respondents included doctors, nurses, laboratory attendants, pharmacists, x-ray technicians and hospital sanitary workers. The total population of $\mathrm{HCW}$ of selected hospitals is over 3,000. An online calculator ${ }^{10}$ was used to determine the sample size of study group, keeping margin of error less than $7 \%$, and confidence level $86 \%$.The calculated sample size was $200 \mathrm{HCW}$.

\section{Questionnaire Survey}

Data were collected using quantitative methods via a structured questionnaire. The questionnaire forms were completed onsite with face to face communication with the respondents. Each questionnaire form took on an average about 10 minutes to complete. The questionnaire was adapted from US Center for Disease Control (CDC), NIOSH as well as hazards reported in literature ${ }^{2,11,12}$. The questionnaire included section on demographic information, smoking status, education status, type of health care facility, duration of work and work experience with respect to hazards. The questionnaire comprised four more sections that addressed ergonomic, biological, physical and psychosocial hazards respectively commonly faced by HCW in the work environment. Moreover, questions on awareness of workers regarding occupational hazards and safety practices as well as control measures in place by the employers to mitigate the potential hazards in the HCFs, were also asked. The survey did not address pre-existing screening of musculoskeletal disorders. 


\section{Consent}

In accordance with the guidelines for conducting such research, consent was obtained from the respondents prior to filling of questionnaire. Onsite surveys were conducted with the permission from the administration of each surveyed facility.

\section{Statistical Analysis}

IBM SPSS version 20 was used to analyze data from the questionnaire survey. Independent variable included type of health care occupation, type of health care facility, work in multiple facilities, work overtime, lifting heavy loads, bending/twisting at work and duration of work experience. Dependent variables included ergonomic hazards including muscle aches, chronic back pain, neck/wrist/ shoulder pain, fracture/body injury, problems in body posture, stretching of muscles. Bivariate correlation was determined. The applied tests were ANOVA one-way and Pearson's chi-square test.

\section{Results}

The results of the survey showed prevalence of various hazards among HCWs including ergonomic, biological, physical and psychosocial. According to the demographic data (Table 1), majority of the HCWs were females $(72.5 \%)$. Respondents comprised majorly nurses (37.5\%) and doctors (32.5\%). Fifty-seven percent respondents belonged to government while $43.0 \%$ were employed in private sector HCFs. Most of the workers (54.5\%) had work experience of fewer than 5 years. The range of working hours varied from 6-10 hours, seven days a week. A number of respondents (43.5\%) also worked overtime and $36.5 \%$ were doing job in multiple health care facilities.

Table 2 summarizes reported $\mathrm{OH} \& \mathrm{~S}$ problems faced by HCW. Ergonomic hazards included muscle aches/ muscle sprains, carpel tunnel syndrome, chronic back pain, elbow/wrist/ hamstring/neck pain, problem of body posture, excessive stretching of muscles, bending/ twisting as well as lifting heavy loads multiple times at work. Biological hazards included experience of cuts/wounds/lacerations, airborne infections, body contact with retroviral patients and specimens, and exposure to blood borne specimens. Physical hazards included trips/falls, exposure to $x$-rays, high noise level and chemical spills, and experience of skin burn. Psychosocial hazards included physical abuse, stress and assaults from co-workers.

Table 3 shows the categorization of reported ergonomic hazards with respect to type of facility and nature of job/work. The results of HCW awareness regarding occupational hazards and safety practices are shown in Table 4. Majority of the workers (85.5\%) had awareness regarding occupational hazards and their categories in the workplace. Postemployment workshops were most common source of occupational hazards among workers (44.5\%). Table 5 identifies control measures in place by the workplace as well as individual protective measures taken by the workers.

Table 1: Characteristics of Health care workers at both Government and private health care facilities of Lahore

\section{Characteristics}

\section{Percentage}

$\%$

\section{Gender}

Male

27.5

Female

72.5

\section{Smoking status}

Smoker

13

Ex- smoker

6.5

Non - smoker

80.5

Health care occupation

Doctor

32.5

Nurse

37.5

Nursing assistant

5.0

6.0

\section{Laboratory attendant}

Pharmacist

Radiographer

2.5

Sanitary worker

3.0

\section{Health care facility type}

Government

Private

\section{Work characteristics}

Work in Multiple facilities

(more than one facility)

Work overtime (more than 8h)

Work experience

$>5$ years

45.5

$<5$ years 
Table 2: Occupational health symptoms prevalent among health care workers

Hazards Percentage

(\%)

\begin{tabular}{lr}
\hline Ergonomic risk factors & \\
Muscle aches/muscle sprains & 76.5 \\
Carpel tunnel syndrome & 27.0 \\
Chronic back pain & 46.5 \\
Elbow/wrist and neck pain & 56.0 \\
Hamstring & 26.0 \\
Fracture & 22.5 \\
Problems of body posture & 56.0 \\
Problem of excessive stretching & 67.5 \\
of muscles & \\
Bending/twisting at work & 55.5 \\
heavy load/ weightlifting & 50.0 \\
Physical & \\
Slips/Trip/Falls at work & 65.0 \\
Exposure to X-ray & 51.5 \\
Skin burns & 30.5 \\
High noise levels & 64.0 \\
Chemical spills & 54.0 \\
Biological & \\
Cuts/wounds/lacerations & 69.0 \\
Direct contact with specimens & 56.0 \\
Body contact with retroviral patient 36.0 \\
Airborne diseases & 64.0 \\
Infectious disease & 72.0 \\
Blood borne pathogens & 21.5 \\
Psychosocial & \\
Psychosocial/physical abuse & 68.5 \\
Assaults from Co-Workers & 43.5 \\
Stress Due to Work & 77.0 \\
\hline & \\
\hline
\end{tabular}

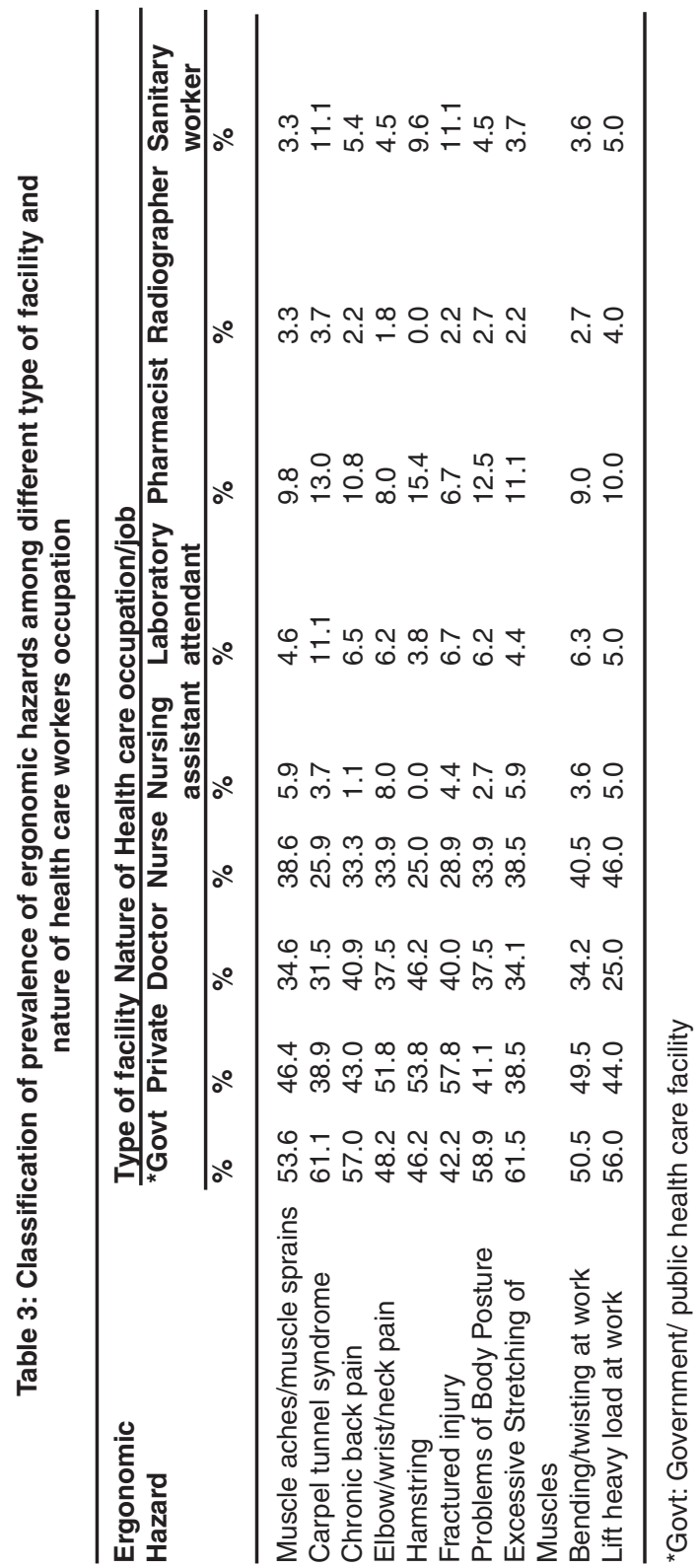

Table 4: Awareness and sources regarding occupational hazards and safety practices

(\%)

Awareness regarding occupational hazard and safety practices

Occupational hazard and category

Occupational infections

Procedures where needle stick injuries are most likely to occur

90.0

Procedures that violate the standard precaution

Occupational cross infection after clinical procedure could be 
prevented by effective hand washing

Sources of knowledge (of respondents)on occupational hazards

Post-employment workshop

Post-employment learning in ward / clinic

Professional training

Posters / handbills

Table 5: Workers responses regarding control measures provided by employer and individual personal protective measures

\section{Control measures provided by employer}

\section{Respondents $\mathrm{n}$}

(\%)

Safety education \&training on all universal precautions

93.0

Safety tools, equipment \& machinery

97.5

Training on all machinery \& equipment used

96.0

Personal protective equipment

95.0

95.5

Individual personal protective measures

BCG Vaccination1

79.5

Hepatitis A Vaccination

81.0

93.5

53.5

Received HIV screening/ examination

\section{Discussion}

The current study showed prevalence of various ergonomic and other hazards among HCW. Majority of the workers were females. Women represent approximately 80 percent of the healthcare workers (HCWs) around the world 5 . Majority of the respondents faced a range of ergonomic hazards in which muscle aches/ muscle sprains (76.5\%), elbow/ wrist/ neck pain (56.0\%), problems of body posture $(56.0 \%)$, excessive stretching of muscles $(67.5 \%)$, bending/ twisting at work $(55.5 \%)$ were the most reported. Other ergonomic hazards included carpel tunnel syndrome $(27.0 \%)$, chronic back pain $(46.5 \%)$, hamstring pain $(26.0 \%)$, injury due to fracture $(22.5 \%)$ and lifting heavy loads of work (50.0\%). This shows prevalence of MSDs among the HCW. However, similar studies show varying results. For instance, literature indicates high prevalence (77\%) of lower back pain (LBP) among different types of HCW ${ }^{13,14,15,16}$. Comparable cross-sectional study conducted among 450 physicians in Iran reported similar ergonomic hazards; LBP (15.1\%), neck pain $(9.8 \%)$ and knee pain (19.8\%), associated with MSD.
Other reported hazards include problems with body posture ${ }^{17}$. Work related injuries including fractures have been found to be most common among nurses and other semi-skilled $\mathrm{HCW}^{18}$. Prolonged awkward or static postures, manual lifting of heavy loads and handling of patients and prolonged standing at work are considered as main causes of work related MSD in $\mathrm{HCF}^{19,20}$. Posture related risks have been reported to pose risk among waste workers also who are involved in waste collection tasks like lifting and dumping of waste ${ }^{21}$.

A significant correlation between muscle aches/ sprains and work in multiple health facilities $(p<0.05)$, muscle aches/ sprains and nature of occupation $(p<0.01)$ was found. Hence, characteristics such as nature of healthcare occupation and work in multiple facilities (more than one facility) are strongly correlated with the occurrence of muscle aches/ sprains among workers. Muscle aches/ muscle sprains were mostly reported among nurses (38.6\%) and doctors (34.6\%) as shown in Table 3. Similarly, positive correlation was found between chronic back 
pain and work in multiple health facilities $(p<0.05)$ as well as working overtime $(p<0.01)$. Significant correlation existed between excessive stretching of muscles and working overtime $(p<0.01)$, work in multiple facilities $(p<0.05)$ and lifting of heavy loads at work $(p<0.05)$. Hazards associated with bending and twisting postures were found to be correlated with type of HCF $(p<0.05)$ which were reported in both government $(50.5 \%)$ and private $(49.5 \%)$ facilities.

Health issues such as neck/back/wrist pain were significantly associated with type of work facility $(p<0.01)$ as well as nature of health care occupation $(p<0.05)$. Total of $51.8 \%$ of such hazards were reported in private sector, mostly among doctors (37.5\%). Injuries due to fractures were found to be significantly correlated with nature of occupation $(p<0.05)$, work in more than one facilities $(p<0.05)$, type of healthcare facility $(p<0.05)$ and overtime work $(p<0.01)$. Injuries resulting from fractures were mostly reported in doctors $(40.0 \%)$ and nurses $(28.9 \%)$ with a higher occurrence in private HCF (57.8\%). A significant correlation was found $(p<0.05)$ between carpel tunnel syndrome and nature of healthcare occupation. Carpel tunnel syndrome was mostly reported by doctors (31.5\%) that comprised dentists. Pain in hamstrings was significantly correlated with nature of healthcare occupation $(p<0.01)$ which was mostly reported among doctors (46.2\%) and associated with working conditions. Hence, the present study showed that work characteristics, such as type of work facility, nature of health care occupation, work in more than one facilities, overtime work, are linked with most of the reported ergonomic hazards.

Generally, characteristics such as working overtime, work in multiple facilities or in multiple shifts is reportedly associated with higher risks of injuries and susceptibility to ergonomic hazards ${ }^{18,22}$. A study conducted among registered nurses and care aides working at full time and part-time work showed that those involved in full time work shifts had higher risks of work related injuries and fractures than those working on a part time basis ${ }^{23}$. Several risk factors such as heavy and prolonged physical activity, increased stress and work demand as well as high body mass index (BMI) are also linked with work related MSDs among workers ${ }^{17,19}$.
In the present study, biological hazards reported included experience of cuts/wounds/ lacerations $(69.0 \%)$, direct contact with specimens $(56.0 \%)$, and experience of airborne diseases $(64.0 \%)$ and other infections $(72.0 \%)$. Although majority of the workers $(90.0 \%)$ were aware of procedures where needle stick injuries are most likely to occur and were knowledgeable on occupational infections and most likely sources of occupational infection as well of the fact that occupational cross infection after clinical procedure could be prevented by effective hand washing (89.5\%). Other studies also support exposure to biological hazards such as injuries due to needles and cuts, direct contact with infectious materials and cuts/wounds due to needles and sharp objects among $\mathrm{HCW}$ s despite having received training in handling sharp objects and infectious material ${ }^{24,25}$.

As regards protective measures, majority of the respondents had received different kinds of vaccinations including $B C G$, Hepatitis $A$ and $B$ vaccinations as well as HIV screening examination. All the facilities had proper control measures to mitigate and reduce the prevalence of biological hazards (Table 5). These included training on the proper use of machinery and equipment, universal precautions and hand washing, provision of safety education, safety tools, a set of personal protective equipment and a separate area for the disposal of medical waste.

With respect to physical hazards, slips/trips/falls $(65.0 \%)$, high noise levels $(64.0 \%)$ chemical spills (54.0\%) and exposure to x-rays (51.5\%) was the most prevalent risks experienced by workers. A study conducted among Zambian HCWs also found exposure to high noise levels, skin contact with chemicals and pesticides as important issues ${ }^{23}$.

The present study also shows workers coming across psychosocial hazards including work related stress $(77.0 \%)$ and some form of psychosocial or physical abuse (68.5\%). Work related stress can be associated with factors such as working overtime, work in multiple health facilities, assault from coworkers and some forms of psychosocial hazards. The prevalence of psychosocial and physical abuse is a reflection of poor work ethics and work 
control in these health facilities. A study conducted among the HCWs of southern India indicated the prevalence of psychosocial hazards in the form of lack of promotions, non-availability of amenities; high workload and poor grievance report and address system $^{11}$.

The survey showed that majority $(85.5 \%)$ of the workers was aware of occupational hazards and their categories as most of the surveyed respondents comprised doctors and registered nurses. Major sources of knowledge and awareness were postemployment workshops (44.5\%), professional workshops (32.5\%) and post-employment learning in ward (15.5\%).

\section{Conclusion}

The present study showed that HCW of both government and private sectors were equally exposed to ergonomics, biological, physical and psychosocial hazards. Majorly reported ergonomic hazards related to symptoms of MSDs which correlated with work characteristics such as nature of occupation, overtime and work at multiple facilities. Biological hazards comprised cuts/wounds/ lacerations, direct contact with specimens, experience of airborne diseases and other infections. Slips/trips/falls, high noise levels, chemical spills and exposure to $x$-rays were frequently reported physical hazards. Work related stress and some form of psychosocial or physical abuse constituted psychosocial hazards prevalent among the surveyed respondents.

Although, all health care facilities had proper control measures to mitigate and minimize biological hazards and majority of the workers were using the provided PPEs. However, there is a need to improve working standards and conditions to reduce the prevailing hazards in these healthcare facilities.

\section{Acknowledgement}

This research received no specific grant from any funding agency in the public, commercial, or notfor-profit sectors. The authors declare no conflict of interest.

\section{References}

1 Connor T H, DeBord DG, Pretty JR, Oliver MS, Roth TS, Lees PS, Clark JC. Evaluation of antineoplastic drug exposure of health care workers at three University-based US Cancer Centers. Journal of Environmental Management, 52(10): 1-9 (2010).

2 Cdc.gov. CDC - Health Care Workers - NIOSH Work place Safety and Health Topic. [online] Available at: https://www.cdc.gov/niosh/ topics/healthcare/default.html [Accessed 15 Oct. 2017]. (2018).

3 Wicker S, Jung J, Allwinn R, Gottschalk R, \& Rabenau HF, Prevalence and prevention of needle stick injuries among health care workers in a German university hospital. International Archives of Occupational and Environmental Health, 81: 347-354 (2008).

4 Mbada CE, Obembe AO, Alade BS, Adedoyin, RA, Johnson OE, Soremi OO, Work-related musculoskeletal disorders among health workers in a Nigerian teaching hospital. TAF Preventive Medicine Bulletin, 11(5): 583-8
(2012).

5 Yasobant S,Rajkumar P, Work-related musculoskeletal disorders among health care professionals: A cross-sectional assessment of risk factors in a tertiary hospital, India. Indian Journal of Occupational and Environmental Medicine, 18(2): 75-81 (2014).

6 Ghosh T, Occupational health and hazards among health care workers. International Journal of Occupational Health and Safety, 3(1): 1 - 4 (2013).

Barr AE, Barbe MF, Pathophysiological tissue changes associated with repetitive movement: a review of the evidence. Physical therapy, 82(2): 173-87 (2002).

8 Gralton J, Rawlinson WD, Louise M. Health care workers perceptions predicts uptake of personal protective equipment. American Journal of Infection Control, 41: 2-7 (2013).

9 da Costa BR, Vieira ER. Risk factors for work-related musculoskeletal disorders: A systematic review of recent longitudinal 
studies. American Journal of Industrial Medicine, 53: 285-323 (2010).

10 Raosoft. Sample size calculator. Seattle (WA): Raosoft; (2004) [cited 2017 August 4]. Available from: http://www.raosoft.com/ samplesize.html

11 Siziya S, Rudatsikira E, Mweemba A, Rachiotis G, Mugala D, Bowa K, Muula, A $S$. Exposure to occupational health hazards among Zambian workers. Occup Med. 63(2): 109-115 (2013)

12 World Health Organization. Occupational health: a manual for primary health care workers. 2002

13 Karahan A, Kav S, Abbasoglu A, Dogan N, Low back pain: prevalence and associated risk factors among hospital staff. Journal of Advanced Nursing, 65: 516-524 (2009).

14 Rathore FA, Rayan Attique YA, Prevalence and Perceptions of Musculoskeletal Disorders Among Hospital Nurses in Pakistan: A Crosssectional Survey. Cureus, 9(1):2017. doi: 10.7759/cureus. 1001

15 Alexopoulos EC, Burdorf A, Kalokerinou A, A comparative analysis on musculoskeletal disorders between Greek and Dutch nursing personnel. International Archives of Occupational and Environmental Health, 79: 2-8. (2006).

16 Picavet HS, Schouten JS, Musculo skeletal pain in the Netherlands: Prevalence, consequences and risk groups, the DMC (3)-study. Pain, 102: 167-78 (2003).

17 Mehrdad R, Dennerlein J.T Morshedizadeh, M. Musculo skeletal disorders and ergonomic hazards among Iranian physicians. Archives of Iranian Medicine, 15(6): 370-374 (2012).

18 Boyer J, Galizzi M, Cifuentes M, d'Errico A, Gore R, Punnett L, Slatin C, Ergonomic and Socioeconomic Risk Factors for Hospital Workers' Compensation Injury Claims.
American Journal of Industrial Medicine, 52: 551-562 (2009).

19 Faber A, Giver H, Stroyer J, Hannerz H, Are low back pain and low physical capacity risk indicators for dropout among recently qualified eldercare workers? A follow-up study. Scandinavian Journal of Public Health, 38: 810-816 (2010).

20 Luime JJ, Kuiper JI, Koes BW, Verhaar JA, Miedema HS, Burdorf A, Work-related risk factors for the incidence and recurrence of shoulder and neck complaints among nursing home and elderly-care workers. Scand Journal of Work Environ Health, 30: 279-286 (2004).

21 Cakit E. Assessment of the physical demands of waste collection tasks. Global Nest Journal. 17(2):426-38 (2015)

22 Burch JB, Tom J, Zhai Y, Criswell L, Leo E, Ogoussan K, Shift work impacts and adaptation among health care workers. Occupational Medicine. 59: 159-166 (2009).

23 Alamgir H, Yu S, Chavoshi N, Ngan K, Occupational injury among full-time, part-time and casual health care workers. Occupational Medicine. 58: 348-354 (2008).

24 Ndejjo R, Musinguzi G, Yu X, Buregyeya, E, Musoke D, Wang JS, Ssempebwa J. Occupational health hazards among healthcare workers in Kampala, Uganda. Journal of Environmental Public Health, 2015: 1-9 (2015).

25 Senthil A, Anandh B, Jayachandran P, Thangavel G, Josephin D, Yamini R, Kalpana, B. Perception and prevalence of work-related health hazards among health care workers in public health facilities in southern India. International Journal of Occupational and Environmental Health. 21(1): 74-81 (2015). 